\title{
Prácticas y saberes ancestrales en torno a la niñez en comunidades afrodescendientes, negras y palenqueras de Bolívar y Sucre
}

\author{
ANCESTRAL PRACTICES AND KNOWLEDGES ABOUT CHILDREN IN AFRO-DESCENDANT, \\ BLACK AND PALENQUE COMMUNITIES FROM THE DEPARTMENTS OF BOLIVAR AND \\ SUCRE \\ PRÁTICAS E SABERES SOBRE A INFÂNCIA EM COMUNIDADES AFRODESCENDENTES, \\ NEGRAS E PALENQUERA DE BOLÍVAR E SUCRE
}

\author{
Rutsely Simarra Obeso* \\ Luis Manuel Marrugo Fruto*
}

\section{Resumen}

En este escrito se abordan algunas prácticas, saberes y actuaciones en torno a la forma en que las comunidades afrodescendientes cuidan, protegen, forman e inician socialmente a los niños.

Para el análisis se tienen en cuanta varios elementos: la cosmovisión, la espiritualidad, el territorio y la naturaleza en conexión con la identidad cultural, la tradición oral, las pedagogías propias y la memoria colectiva, como evidencias y recorridos de modos otros de pensar, enseñar, aprender, transmitir, reconocer y autorreconocerse dentro de escenarios culturales ancestralmente afrodescendientes.
Palabras clave

cultura; afrodescendientes; negros; palenqueros; cosmovisión; infancias; prácticas y saberes ancestrales; pedagogías propias; tradición oral; memoria colectiva

Como referentes para abordar la descripción de los saberes frente a las prácticas de crianza de los niños afro, negros y palenqueros, se tienen en cuenta concepciones sobre: cultura, algunos planteamientos del paradigma decolonial -principalmente los relacionados con las epistemes otras, como formas de resistencia a la colonialidad del poder, del saber, del ser-, y además lo que respecta a prácticas y saberes ancestrales a través de los cuales se difunde la cosmovisión, las tradiciones y concepciones.

La información analizada corresponde a los recuerdos y experiencias de maestros afrodescendientes que habitan y laboran en estas comunidades, con ellos se llevó a cabo una capacitación que sirvió como pretexto para indagar en la memoria colectiva aspectos de la relación infancia/cultura de los cuales se derivaron un conjunto de conocimientos en torno a la salud, la alimentación, la convivencia, y los rituales de vida y muerte.

\footnotetext{
* Corporación Universitaria Rafael Núñez, Cartagena, Colombia. Correo electrónico: rutsely.simarra@curnvirtual.edu.co

** Fundación Instituto de Educación e Investigación Manuel Zapata Olivella, María La Baja, Bolívar, Colombia. Correo electrónico: marrugofruto@gmail.com
} 


\section{Abstract}

This paper addresses some practices, knowledge and actions about the way children are cared for, protected, educated and introduced to society in African descendant communities.

Several elements are considered for the analysis: world view, spirituality, territory and nature in connection with cultural identity, oral tradition, own pedagogies and collective memory, such as evidence and reviews of other ways of thinking, teaching, learning, transmitting, and of recognizing others and themselves in ancestrally African descent cultural settings.

A number of conceptions are used as referents to address the description of knowledge about the rearing practices of African, black and Palenque children, including conceptions about: culture, some approaches from the decolonial paradigm-mainly those related to other epistemes as forms of resistance to the coloniality of power, of knowledge, of being-, and also with respect to ancestral practices and knowledge through which the world view, traditions and conceptions are spread.

The analyzed information corresponds to the memories and experiences of African descendant teachers who live and work in these communities, with whom we had a training session. This session served as a pretext to search the collective memory of the teachers for aspects regarding childhood/culture, from which a knowledge base about health, food, coexistence, and life and death rituals was derived.

\section{Resumo}

Neste texto são abordadas algumas práticas, saberes e atuações sobre a forma na que as comunidades afrodescendentes cuidam, protegem, formam e iniciam socialmente às crianças.

Para a análise, são levados em conta vários elementos: a cosmovisão, a espiritualidade, o território e a natureza vinculada à identidade cultural, à tradição oral, às pedagogias próprias e à memória coletiva, como evidências e percursos de outros modos de pensar, ensinar, aprender, transmitir, reconhecer e se auto-reconhecer dentro de cenários culturais ancestralmente afrodescendentes.

Como referências para abordar a descrição dos saberes frente às práticas de educação das crianças afro, negros e palenqueros, são levados em conta os conceitos de: cultura, algumas abordagens do paradigma decolonial -principalmente aqueles relacionados com as epistemes outras, como formas de resistência à colonialidade do poder, do saber e do ser-, além daquilo relacionado às práticas e saberes ancestrais através dos quais se difunde a cosmovisão, as tradições e concepções.

A informação analisada corresponde às lembranças e experiências de professores afrodescendentes que moram e trabalham nestas comunidades. Uma capacitação foi realizada com os professores, a qual foi pretexto para indagar na memória coletiva alguns aspectos da relação infância/cultura, dos quais se derivou um grupo de conhecimentos sobre a saúde, a alimentação, a convivência e os rituais de vida e morte.

\section{Keywords}

culture; African descendants; black people; Palenque people; world view; childhood; ancestral knowledge and practices; own pedagogies; oral tradition; collective memory

\section{Palavras chave}

cultura; afrodescendentes; negros; palenqueros; cosmovisão; infâncias; práticas e saberes ancestrais; pedagogias próprias; tradição oral; memória coletiva 


\section{Introducción}

Los referentes alrededor de la concepción de infancia en las comunidades afrodescendientes de San Onofre, Mahates, María La Baja y Palenque, en los departamentos de Bolívar y Sucre, de acuerdo con el análisis de recuerdos y experiencias vivas de algunos miembros de estas comunidades, han de centrarse en varios elementos complejos: por un lado, la cosmovisión como una forma particular de ver, concebir y asumir el mundo; por otro, la espiritualidad cargada de las sinergias entre lo terrenal y lo sobrenatural, el territorio como espacio de realización cultural, y, a su vez, la relación amigable de los afrodescendientes con la naturaleza y sus bienes. Estos elementos conectados entre sí, vinculados con las referencias a la identidad cultural, a la familia y a la tradición oral, y difundidos a través de las pedagogías propias, permiten acercamientos a la forma en que se concibe la niñez, en correspondencia con una visión particular de mundo que determina imaginarios, relaciones y roles sociales bajo los parámetros de la cultura. Estas formas de comprensión de la realidad se conectan con el reconocimiento de epistemes otras, vinculadas a un sistema mundo, en el cual se visibilizan lógicas y modos de conocer, pensar, ser y vivir, distintos a las epistemes occidentales instauradas y difundidas a lo largo de la historia, de manera imperativa, tal como se analiza y critica en las reflexiones del paradigma decolonial, en lo que respecta a la colonialidad del poder, del saber y del ser, desde cuyas lógicas el conocimiento de otras expresiones culturales, sobre todo étnicas, son negadas, estereotipadas, invalidadas, discriminadas y reducidas. Sin embargo, por su misma naturaleza de raigambre cultural, algunas de estas formas otras de elaborar conocimiento, se hacen resistentes a su invisibilización, recreándose y retransmitiéndose en la vida de muchas comunidades sin perder vigencia.

La niñez, como parte fundamental del ciclo de vida en comunidades afrodescendientes, da cuenta de las conexiones que se han tejido en torno a su existencia, en estrecha correspondencia con un sinnúmero de aspectos, como el tiempo, los símbolos, el cuerpo, los astros, el ecosistema, los sentimientos, el peligro, la muerte, lo sobrenatural, las normas, los valores e ideales, etc., que se dimensionan en el proceso de crianza y socialización de los pequeños.
A propósito del creciente interés que ha venido suscitando la infancia en diferentes ámbitos del desarrollo social en el mundo, la pregunta por los imaginarios que subyacen en la manera en que cada cultura visualiza, contextualiza y construye sus propios discursos y prácticas de crianza, resulta de gran valor, por cuanto pone en relieve la relación entre infancia y cultura como un eje importante para la comprensión de este trascendental asunto.

En este sentido, y para construir la reflexión que se propone en el artículo, se consideran tres aspectos para el análisis y la comprensión del tema. En primer lugar, cabe señalar que los saberes que cimientan una visión del ser colectivo e individual en las comunidades afro, los significados y simbologías que se tejen, recrean y difunden, los referentes de identidad que se construyen, deben ser comprendidos en el marco de la cultura para poder establecer sus verdaderos significados. En esta medida, las concepciones sobre infancias afro y las formas en que la comunidad actúa en correspondencia con estas, reafirma lo que Geertz (2003) propone sobre la cultura,

[Esta] denota [...] una entramada de significados transmitidos históricamente, personificados en símbolos, un sistema de concepciones heredadas expresadas en formas de símbolos, por medio de las cuales los hombres se comunican, perpetuán y desarrollan su conocimiento de la vida y sus actitudes con respecto a esta. (p.88).

Es posible decir que un determinado espacio cultural todo significa, todo tiene valor para sus integrantes.

En segundo lugar, en el documento se visibiliza y valora el conocimiento elaborado en el contexto sociocultural afro, que se enmarca en las epistemes otras que se construyen como formas de conocimiento, que se sitúan histórica y corporalmente en el territorio; en este caso, el territorio afrodescendiente en los departamentos de Bolívar y Sucre.

Este saber situado, salvaguardado y transmitido ancestralmente corresponde a lo que Restrepo y Rojas (2010) recogen como parte de los planteamientos esbozados por la comunidad de argumentación decolonial, cuando exponen que "la inflexión decolonial se piensa como un 
paradigma otro, que tiene en consideración la geopolítica y la corpopolítica, esto es, la situacionalidad geohistórica y corporalizada que articula la producción de conocimiento". (p. 20). Y es en esta articulación que los conocimientos alcanzan su esencialidad y trascendentalidad en la comunidad en que tienen lugar.

En tercer lugar, se tendrán en cuenta en el texto planteamientos asociados con las prácticas culturales de saberes ancestrales que identifican maneras propias de conocer y difundir el conocimiento, articuladas con la tradición oral y con la memoria colectiva, histórica y ancestral que en esencia recogen los elementos concretos de las pedagogías propias; estas pedagogías o prácticas de enseñanza comunitarias, de acuerdo con Hernández et al. (2016),

[...] están constituidas por prácticas y mecanismos construidos históricamente por la comunidad y constituyen la forma predilecta de educar a los hijos e hijas. Entre estos dispositivos resaltamos el consejo de los mayores, la narración de vivencias por los padres, y algunos propios del aprendizaje lúdico. Todos estos elementos están cruzados por la tradición oral que caracteriza a las culturas de las colectividades étnicas y culturales, la cual permite de generación en generación reproducir la sabiduría ancestral que reposa herméticamente en la memoria colectiva y que aflora acorde con las circunstancias que moldean su sentir, pensar y actuar. (p. 30).

En este contexto la memoria colectiva cumple un importante papel puesto que es a través de su activación que se despliegan los saberes que entrañablemente se han venido transmitiendo de generación en generación; saberes que en algunas comunidades afrodescendientes de Bolívar y Sucre continúan superviviendo "pensando y viviendo decolonialmente a pesar del poder colonial" (Walsh, 2013, p. 25), conectados con la historia y la vida de la comunidad, marcados tanto por el legado ancestral africano como por otras herencias.

El escrito que se presenta es el resultado del trabajo desarrollado con docentes en los módulos "Procesos de socialización en la población afrodescendiente" y "Tradición oral y lúdica (oralitura)" en el marco del Diplomado sobre Etnoeducación para la Población Afrocolombiana, en San Basilio de Palenque (Bolívar) y San Onofre (Sucre), Ilevado a cabo a finales de 2013, además de permitir la difusión de algunos referentes teóricos, conceptuales y experiencias sobre la etnoeducación y de los afrodescendientes en el Caribe y Colombia, sirvió como pretexto para interrogar la memoria colectiva, histórica y ancestral con respecto a la relación entre infancia y cultura.

En este espacio de formación participaron docentes de instituciones educativas del Estado, provenientes de los municipios de María La Baja, Mahates, San Onofre y del corregimiento de San Basilio de Palenque, con la experticia de sus experiencias se construyeron acercamientos a ciertas prácticas que se reelaboran en estas comunidades afrodescendientes con respecto a la infancia. Como resultado del diálogo de saberes construido y a partir del ejercicio de consulta a la memoria colectiva, tanto maestros como maestras aportaron anécdotas y vivencias de sus comunidades, asociadas con la infancia, al igual que señalaron algunas prácticas pedagógicas comunitarias para la vinculación social de los infantes a sus respectivos escenarios de convivencia.

El análisis que se construye muestra que las referencias a la identidad cultural, la familia (nuclear y extendida) y la oralidad cumplen un papel importante en la comprensión de las concepciones alrededor de la infancia y los procesos de socialización de los pequeños. Desde lo que se hace, se dice y se piensa es posible comprender la conexión estrecha entre cosmovisión, espiritualidad y naturaleza como elementos sustanciales en la construcción de las concepciones sobre la infancia.

En lo que respecta a la identidad, podemos señalar de acuerdo con Molano (2006), que

El concepto de "identidad cultural" encierra un sentido de pertenencia a un grupo social con el cual se comparten rasgos culturales, como costumbres, valores y creencias. La identidad no es un concepto fijo, sino que se recrea individual y colectivamente, y se alimenta continuamente de la influencia exterior. (p. 79).

En esa medida, configura formas de actuación, difusión, protección y defensa hacia las tradiciones que transitan de generación en generación. 
El patrimonio cultural oral, material e inmaterial a partir del cual es posible descubrir matices de ese sentido de pertenencia, se lee en las prácticas y saberes culturales desde los cuales cada integrante piensa y elabora sus actuaciones en torno a su comunidad; de este modo, la cosmovisión, la religiosidad, el territorio, las relaciones con la naturaleza, lo ético, lo estético, la gastronomía, las relaciones sociales, las formas de comunicación, los objetos y un conjunto de prácticas simbólicas representativos constituyen un componente importante para comprender diferentes aspectos de los diversos grupos humanos, entre estos, la manera como se concibe y se vive con los pequeños en el espacio de la comunidad.

En cuanto a la familia, es pertinente señalar que para los afrodescendientes en referencia, este núcleo social es una instancia de reafirmación y de reproducción de la cultura, de las normas y paradigmas de convivencia. La familia tiene como principal propósito garantizar la continuidad de los saberes, la identidad, la defensa del territorio, la apropiación de las tradiciones; así mismo, impulsar acciones de control social entre sus miembros en búsqueda de la cohesión social de la comunidad; para ello se cimienta en su cosmovisión a través de las voces de los mayores, líderes importantísimos en la transmisión de la cultura en las distintas generaciones.

Un ejemplo concreto de este paradigma puede ubicarse en la visión del pueblo negro de San Basilio de Palenque, para este grupo étnico, la familia

[...] es el espacio primordial de socialización primaria donde los individuos nacen y encuentran sus primeras interacciones sociales. En la familia como en la sociedad palenquera los mayores tienen liderazgo y son quienes determinan el rumbo de la misma. Tienen el respeto de los demás miembros y gozan de la sabiduría ancestral que transmiten oralmente. (Hernández, Guerrero y Pérez, 2008, p. 76).

En ese sentido, este núcleo social es el encargado de que a los hijos se les forme e instruya en el marco tanto de la cotidianidad como de la ancestralidad; es la instancia clave en la cual los agentes de socialización (padres, abuelos, tíos, hermanos, la familia extendida), construyen prácticas de crianza basadas en los principios de convivencia, dirigidas a la enseñanza de los lenguajes y los sistemas de significado, a los sentimientos, a los bienes, a la atención de las personas, pero también dirigidas a la economía, al trabajo, y al reconocimiento de la autoridad y los liderazgos, entre otros aspectos.

Los mecanismos de los que se ha valido y apoyado la familia para enseñar y difundir estas prácticas y saberes alrededor de la infancia y de las otras manifestaciones de su patrimonio cultural, han sido las pedagogías propias o modelos de enseñanza creadas por los mismos pueblos para compartir su acervo de tradiciones

A través de las formas propias de enseñanza se busca que los saberes de la tradición familiar sean asumidos como fuente genuina de conocimientos, teniendo en cuenta que "todos los hechos y acontecimientos son fuente de reflexión y de aprendizaje para la vida desde aquellos de carácter animístico como los sueños, hasta los de índole material, como la naturaleza y sus ritmos" (Aguilar y Rodríguez, 1999, p. 88), por ello los principales difusores del acervo con toda su carga existencial son los mayores, quienes tienen la tarea de dar a conocer los fundamentos y esencias de su cultura, de comunicar la historia, la vida y los legados ancestrales para insertarlos en las mentes y las voces de las generaciones siguientes. Cabe señalar que en esta pedagogía las concepciones, prácticas y métodos propios de la comunidad "[...] están compuestos y sustentados por dos ejes: uno, de carácter general, que corresponde a los derechos de tradición familiar, y el otro, de características particular, a las relaciones de interés, vocación y participación" (p. 88).

En esta misma línea es preciso decir que en este modelo es la tradición oral, una herramienta importante para la difusión de la cultura a través de la cual se divulga la cosmovisión con todas sus elaboraciones, a la vez que es posible transmitir las maneras de ser, sentir, vivenciar e interpretar realidades propias. Para Valverde (2005), "la tradición oral nos permite conocer no solamente los valores, conducta y creencias de un pueblo; también nos permite adentrarnos en la memoria histórica de una ciudad, de una casa o de una comunidad" (p. 105). $Y$ es esa memoria histórica la que hace que por medio de canciones, historias, dichos, anécdotas los miembros del colectivo tengan presente sus referentes de identidad. Desde la memoria colectiva entonces, se recrean 
[...] recuerdos de los ancestros -andrógenos, hombres y mujeres, líderes y lideresas, sabios, sabias, guías- que con sus enseñanzas, palabras y acciones, dieron rumbo al menester pedagógico de existencia digna, complementaria y relacional de seres -vivos y muertos, humanos y otros-con y como parte de la madre tierra. (Walsh, 2013, p. 26).

Otro componente fundamental en las pedagogías propias es el ejemplo, el hacer, a partir del cual los afrodescendientes explican gran parte de los modos de ser en la cotidianidad de la comunidad, posibilitando que se aprendan los roles, las artes, los oficios para poder llevar a cabo las tareas que culturalmente han estado presentes en la caracterización del grupo étnico. De acuerdo con Aguilar y Rodríguez (1999),

En el modo en que se transmite el conocimiento se hace el relevo de unos miembros de la familia a los otros; de los mayores a los menores cuando éstos están en condiciones y lo suficientemente entrenados para ser responsables de la tradición. (p.88).

Para dar cuenta de cómo en las comunidades negras focalizadas se construyen las relaciones con la infancia, se presenta una muestra de los aspectos que conciernen al cuidado, la atención la salud, a los valores del respeto y la solidaridad, así como a las tradiciones para salvaguardar la vida de los pequeños y acompañarlos en caso de fallecimiento.

Las reflexiones que se elaboran en esta parte del documento circulan en un lenguaje del presente y de las remembranzas, la razón de este movimiento se justifica en las voces de los que cuentan las experiencias, en tanto que algunas prácticas y saberes se mantienen vigentes y otras forman parte de las evocaciones de los participantes. Se reitera desde aquí, el hecho de que estos conocimientos operan y encuentran su escenario privilegiado en el espacio concreto María La Baja, Palenque, Mahates, San Onofre, puesto que la cultura también está ligada a lo local, a la geografía, a la historia, a la memoria colectiva, a las significaciones y representaciones sociales..

A continuación se comparten algunas experiencias de los maestros en cuanto a la relación infancia/cultura en comunidades afrodescendientes, negras y palenqueras.

\section{El cuidado, el alimento y la salud: una aproximación a las experiencias de atención y protección de los niños afrodescendientes}

La crianza en algunas de las comunidades afrodescendientes referidas se desarrolla con un fuerte compromiso de la familia y de la comunidad, desde el momento de la gestación hasta cuando la madre da luz e inicia la formación del pequeño.

El ciclo de cuidado del nuevo ser va desde los consejos de las abuelas hasta el de los adultos del círculo más próximo a la madre gestante; estas personas suministran precisiones producto de su experiencia sobre la alimentación, los cuidados, los rituales de protección y las responsabilidades que se asumirán en el entorno familiar. Los conocimientos que se actualizan en la voces de estos protagonistas han sido apropiados a través de la oralidad, y como ocurre en estas comunidades afrodescendientes -rurales en su mayoría-, casi siempre, por medio de: hacer, vivir, decir, volver a re-narrar a otros las experiencias culturales almacenadas en la memoria colectiva, histórica y ancestral desde la cual se coloca en evidencia los conocimientos aprendidos en los íres y venires de la interacción en comunidad.

Desde y con estos elementos de vida y cotidianidad se ha garantizado la vigencia de los saberes, su valorización dentro del entorno cultural, y más aún, la certeza en la veracidad, validez y complejidad de aquellos. Así como lo hicieron saber en su momento los docentes etnoeducadores de Bolívar y Sucre, quienes a pesar de poseer formación académica, elaborada en escenarios de reproducción de la colonialidad del poder, el saber y el ser, reivindicaron y reconocieron un cúmulo de saberes fundamentados y asumidos desde su ancestralidad afrodescendiente.

En lo que continúa del texto se presentan las experiencias de conocimiento y prácticas alrededor de la infancia marcadas por maneras otras de conocer, sustentadas en la cosmovisión, las concepciones e imaginarios del ser otro. 


\section{Cuidados para la atención y la socialización} de los infantes

De acuerdo con las tradiciones y costumbres recogidas con respecto a las atenciones que se han de brindar a los niños, cabe señalar que, estrategias como la repetición o cantaleta, la remembranza de historias pasadas, las ejemplificaciones y las alusiones a hechos concretos, las anécdotas de personajes suelen convertiste, en las poblaciones referenciadas, en los puentes a través de las cuales se comparte información para el actuar, el reconocer y el asumir posturas para el cuidado y la protección de los niños.

Frente a estos saberes, se suele informar tanto a las madres primerizas como a las que ya han tenido hijos, las recomendaciones para la atención de niños antes y después del parto, y en la fase de crecimiento. La palabra anecdótica e ilustrativa suele ser el mecanismo que madres, abuelas, vecinas, parteras y acompañantes comparten con las mujeres que asumen el rol. Como se puede advertir, esta tarea es casi que exclusivamente femenina.

Entre las observaciones aportadas por los docentes se enlistaron las siguientes pautas para asistencia de los infantes en particular de los recién nacidos:

- "No se les puede exponer al aire libre", puesto que el sereno de la noche podría resfriarlos o causarles cólicos.

Es esta la razón para que los mayores insistan en que a los recién nacidos no se les debería sacar a la calle antes de que cumplan los cuarenta días de vida, porque pueden ser víctimas de "mal de ojo".

- Todos los alimentos e implementos que se utilizan para el pequeñito deben ser hervidos.

- Los recién nacidos deben permanecer con gorros, guantes y el ombligo tapado para que no "cojan infecciones".

- A los pequeños no se les puede bañar con agua tibia.

- Los pañales de tela deben ser lavados en las primeras horas de la mañana y ser recogidos antes del mediodía, para que al menor no se le presenten diarreas. Estas prendas jamás podrán ser lavadas con agua de lluvia.

- Diariamente antes de que el reloj marque las diez de la mañana, a los bebés se les debe sacar a tomar un baño de sol; inicialmente se busca la conexión entre estos y el medio ambiente, pero también se hace con el propósito de evitar, entre otras situaciones, que los ojos de los pequeños se tornen "amarillentos o verdosos" o que presenten una apariencia pálida de su piel.

- Cuidar el sueño del pequeño, acostarlos de medio lado o boca abajo en la medida en que van creciendo, esto para salvar que se ahogue con vómitos o por congestión nasal.

- "Darles hamaca", es decir, mecerlos con constancia para que concilien más rápido el sueño y de esta manera puedan permitir a las madres realizar los oficios caseros.

- Evitar que mujeres que hayan tenido relaciones sexuales la noche anterior o que se encuentre menstruando carguen a los pequeños, esto puede incidir en que contraigan "pujo".

Al detallar estas experiencias se puede leer en el marco de las lógicas otras, del imaginario y referencias colectivas, un discurso, unas prácticas y unos saberes que parten de la idea de ver a los infantes como posibles víctimas indefensas a las que se debe brindar protección en el orden de los temporal, los contactos con otras personas, la higiene, los medios para sanar, con los cuales es posible limitar, evitar y proteger a los pequeños de las agresiones del medio.

Otro aspecto relevante en los procesos de socialización de los pequeños, tiene que ver con los rituales de iniciación que forman parte de las acciones comunitarias para la socialización de los infantes, con estos procedimientos se aspira a que los niños aprendan los parámetros, patrones, pautas y normas requeridos para la interacción comunitaria, impulsar la madurez y el desarrollo social de los menores. 
En esta fase de iniciación, por ejemplo, el asunto de las identidades, en términos de género, se va cimentando en la medida en que los nuevos integrantes van avanzando en su crecimiento. Así, se aprenden los roles masculino y femenino. Para el caso de los hombres, a través del juego en el que se simulan huertas o corrales con animales como vacas, toros, caballos elaborados con totumos, ramas de árboles, semillas, tierra; que acompañen a los padres en las labores del campo para la formación física y la adquisición de aprendizajes conectados con los oficios. De igual forma se les incita a los pequeños a jugar con otros niños, motivándolos a medir fuerzas compitiendo en carreras u otras diligencias en las que se expresan destrezas físicas.

En cuanto a las niñas se les orienta a permanecer con otras mujeres de su edad para recrear actividades como "cocinaditos", es decir, preparaciones que realizan las pequeñas con hojas, flores y raíces utilizando, en primera instancia, juguetes infantiles, y más adelante utensilios de verdad, en los que aparecen los fogones, calderitos, vituallas y ciertos referentes de la gastronomía criolla.

En los juegos de roles, es común que las niñas actúen en el papel de la "mamá", simbolicen la atención a los hijos, la casa, los rituales y otras prácticas habitualmente femeninas. Las señoras tienen la tarea de explicar y advertir sobre la circulación adecuada en comunidad en términos de la dignidad, la valoración de la persona, la economía, entre otros aspectos.

Los aprendizajes en esta etapa continúan al generar condiciones para que los menores ganen independencia; así, pues, se les permite a los infantes que interactúen con otros niños, conozcan los lugares del pueblo, visiten a familiares e inicie paulatinamente su integración a la vida social.

\section{La alimentación: sustento por la vida}

Como ya se había señalado, la cultura como escenario amplio de recreación de las identidades, de los gustos, de las concepciones, del ser parte de una comunidad va mostrando los distintos elementos y recursos con los cuales se logra tener "sentido de pertenencia" e identificación con un determinado lugar. Cada recurso inmaterial o material logra su razón de ser por lo que ofrece el territorio y las formas como se interactúa con y junto a él.
La comida, su preparación y suministro, sobre todo para los pequeños afrodescendientes, se constituye en un verdadero sustento por la vida y su aprendizaje se logra con mayor representatividad en la práctica diaria.

De acuerdo con lo anterior, la nutrición es uno de los compromisos de ser padres, que se realiza con mayor atención en las comunidades afrodescendientes exploradas. Si bien la leche materna es el principal alimento para el sustento del bebé, se aclara que esta no "sostiene a los niños", porque no es suficiente para hacerlo sentir satisfechos; por eso, otros tipos de preparados ayudan a cumplir el ciclo de nutrición de los chicos. Bebidas limpias, cocimientos, "tomas", papillas, mazamorras, entre otras, preparadas con plátano, arroz, leche de vaca, panela, raíces o plantas, suelen ser las opciones para alimentar a los nuevos miembros de la familia.

Los cocimientos que se hacen con estos insumos naturales deben producirse con las normas de higiene indicadas y alcanzar un adecuado punto de cocción, de lo contrario, señalan las expertas -abuelas, madres, mujeres mayores-, se pueden enfermar al pequeño, ocasionándole vómitos, cólicos, diarreas y otros malestares.

En el acto concreto de alimentar, las abuelas son las más insistentes en incentivar el consumo de leche materna en los niños, hasta llegado el año o más, si es que todavía se puede "ordeñar a la parida". Después de los veinte días de nacidos, las mujeres avalan el suministro de tomitas de manzanilla o de agua de panela "tibiecita", esto con el objetivo de "entonar" el estómago.

Cuando los niños están más creciditos, se permite que consuman bebidas como las de chicha de arroz "clarita", para que al mes o un poquito después, puedan alimentarse con "mazamorra de topocho" 1 . Se recomienda que para esta papilla, el topocho sea colocado al sereno, al día siguiente se le pase por el rayador, para que finalmente sea puesto al fuego con leche de vaca; mientras hierve se debe revolver constantemente con palote o molinillo de palo, y adicionarle unas astillas de canela.

Al llegar los tres meses del crecimiento, se estila para los menores, suministrarles sopas -pasadas por el colador o por un pedazo de tela-, brindarles alimentos más sólidos;

1 Variedad de plátano. 
asimismo ponerles a degustar sabores "pasándole el dedo por la boca", de manera que el universo de gustos empiece a ser parte de los conocimientos que se van adquiriendo durante el desarrollo.

Desde los cinco meses en adelante se abren las puertas para que los bebés disfruten de los jugos de frutas, coladas de trigo y otros granos; en este momento tiene lugar el consumo de "comidas de sal", es decir, permitir a los menores degustar en pequeñas cantidades los alimentos que consumen los adultos. Poco a poco, los niños se vuelven autónomos en consumir las viandas que le suministran sus padres, cuando muestran dominio de sus manos tomando con alegría y dinamismo "tanto el plato como la cuchara".

La experiencia de las abuelas recuerda que una mala alimentación puede ser causal de los padecimientos y las enfermedades que debilitan a los menores; por ello, cuando las mujeres son inexpertas, las ancianas están atentas a dar consejos para las buenas preparaciones, o a intervenir para corregir los impases. A través de la alimentación señalan las expertas se hace una apuesta por la vida; por cuanto, entre mejor se nutra a los niños menos dificultades de salud atormentará a las familias.

\section{La salud: entre la sabiduría ancestral, los bienes} de la naturaleza y la experiencia comunitaria

La salud de los menores es una condición que ocupa y preocupa enormemente a la familia, en ese sentido, la atención de los padecimientos en los pueblos afro en referencia, recurren a la espiritualidad (rezos, sueños, revelaciones), a la fauna y a la flora del territorio, a la fuerza de la palabra y a los sabedores que median entre la dificultad y los beneficios.

La medicina tradicional ha estado presente en las prácticas curativas de indígenas y afrodescendientes, estos hombres y mujeres han creado disímiles mecanismos, producto de su contacto con los bienes de la naturaleza. Aquellos cuyos ojos han sido dotados de luz pueden ver en los caminos, en los traspatios o en el monte las plantas, semillas, raíces, ánimas, difuntos e, incluso, animales con los que se pueden resolver diferentes padecimientos físicos e incluso internos.
La mayoría de las veces los tratamientos con plantas están ligados a la espiritualidad, a la palabra silenciosa que ayuda a que el enfermo sane. Siguiendo a Hernández, Guerrero y Pérez (2008), "las prácticas religiosas y medicina tradicional son dos caras de una misma moneda, y son de uso importante para el tratamiento de algunas enfermedades o recaídas, sobresaliendo las que tienen como fundamento el rezo y la herbología [...]" (p. 134).

Para la atención y protección de los infantes los sabedores, se han ideado infinidades de recetas con la mediación de los recursos de la naturaleza, estas fórmulas se cuecen con la presencia de las plantas, las palabras sanadoras y la fe tanto del que cura como de los que creen en la cura. Algunas de estas fórmulas pueden ser preparadas solo por los expertos, mientras otras pueden prepararse en el calor de la casa. En la actualidad, en estas comunidades afrodescendientes la medicina tradicional suele combinarse con la medicina alopática.

Como se puede deducir, el campo de la salud es uno de los que mejor ha mostrado las sinergias entre los recursos naturales y la palabra con fe, como opción sanadora y como instancia de maneras otras de construir el conocimiento. La sabiduría ancestral de los abuelos construida a partir del reconocimiento de lo que brindaba la naturaleza, paralelo al sincretismo entre lo religioso y lo mítico, y la validez conferida a estos saberes en la comunidad, hace evidente las rupturas entre las epistemes universales blancas europeas como única ruta de conocimiento para consolidar en contextos más reducidos epistemes locales, rurales afrodescendientes consideradas como formas otras de saber.

Algunas de las experiencias que se registraron en las voces de maestras y maestros con respecto al tema de la salud y la sanación de los infantes fueron las siguientes:

- La conciliación del sueño se logra con distintas "tomas" o bebedizos que se suministran a los pequeños. Estos pueden ser cocimientos con lechuga roja, manzanilla o panela revuelta con hojas de la planta de tilo.

- Para atender casos de diarrea se coloca cataplasmas de yuca y orines en el abdomen de los pequeños. 
- En casos de gripa se proporcionan bebidas de la planta de la verbena, preferiblemente "machucá"2. Así mismo, en esta situación se apela a echar orines en la "mollera" del pequeño o a colocar alrededor del cuello un collar de ajos.

- Los purgantes más apropiados, según los adultos, se pueden suministrar alrededor de los ocho meses, algunos de los acostumbrados son los de piña con leche de magnesia y el de la planta de sen revuelto con panela. Los saberes ancestrales establecen que los preparados para limpiar o purgar deben suministrarse teniendo en cuenta los ciclos de la luna.

- Cuando el niño o la niña tiene gases o está "aventado", se le hace una toma con manteca "colorá", extraída de la planta de la coroza.

- Para contrarrestar "el pujo" o los quejidos de los niños, se debe ubicar a los menores en un cesta y pedirle a tres mujeres vírgenes que saltan de un lado al otro, por encima del recién nacido.

- En el asunto de la dentición se recomienda cortar las uñas de las manos los lunes para evitar la diarrea; también se suele untar tomate con azúcar para disminuir la picazón en las encías.

- Cuando aparecen las infecciones en la boca se suele, y se solía, untar el jarabe de Borax para contrarrestar a los agentes infecciosos.

- Los baños tibios de asiento producto del cocimiento de plantas de "matarratón"3 y guandul4 suelen considerarse para sacar los resfriados.

- Para no afectar la vista de los pequeños en las noches, las madres deben forrar los bombillos en la habitación con papeles de colores, de esta manera

2 Machacada.

3 El matarratón, cuyo nombre científico es Gliricidia sepium, pertenece a la familia de los Fabaceae. Es un árbol originario de Centro América y de la zona norte de Suramérica (véase: http://www.corpoica.org.co/ sitioweb/Archivos/Publicaciones/Matarraton.PDF)

4 El guandul, gandul, guandú, fríjol de palo o quinchoncho es una leguminosa arbustiva de hojas alternadas trifolioladas. Se discute sobre si su origen es África o la India, pero se cultiva hace por lo menos 3000 años (véase: http://es.wikipedia.org/wiki/Cajanus_cajan). no se concentrará la atención de ellos en esta luminosidad. En cuanto a las irritaciones en los ojos, una buena cura se elaboraba con gotas de "matarratón" que se dejan caer en los órganos afectados. Durante el tiempo de la infección se debe evitar que la leche materna llegue a la vista.

- Se recuerda también los baños de leche para asentarles el color de la piel.

- Los dolores de estómago, fiebres u otros malestares suelen ser tratados con "baños" elaborados con raíces y plantas en cuya aplicación no puede faltar el respectivo santiguo.

- En casos de estreñimiento, las abuelas colocan "calillas" o enemas elaborados con hojas de tabaco para estimular la salida de excremento y afectar en lo menor posible la tranquilidad del pequeño.

- Si se presenta un crecimiento exagerado del ombligo se coloca en la zona un botón cubierto por un esparadrapo.

- Cuando las extremidades han sido maltratadas o "descompuestas", se lleva a los niños a donde el rezandero para que sobe y rece la parte afectada y señale posteriormente las recomendaciones respectivas.

- Para evitar que les "entre el frío" a los niños en las noches se amarraban cinticas de cepa de plátano en el cuello y en las manos.

- A las madres lactantes en caso de estar acaloradas, se les recomendaba antes de dar leche a los pequeños, refrescarse, lavarse los senos y meterse a la boca un tantico de sal.

- Los estímulos psicomotrices también forman parte del listado de encargos que toda familia debe saber para solucionar situaciones caseras; por ejemplo, en caso de que los niños presenten retardos a la hora de caminar los saberes ancestrales consideran con buenos ojos untar en las rodillas y en la cintura manteca de chivo tibia. 
- Si el retraso se manifestaba en el lenguaje se invita a los infantes a lamer el "palote" o palo de madera. Además se indicaba que antes del primer año de edad no se podía cortar el cabello porque esta acción incide negativamente en el desarrollo del lenguaje.

Los saberes creados para la sanación han sido pensados para conciliar, reanimar, volver a insertar a través de la mediación de los astros (la luna en sus movimientos), los fluidos corporales, las plantas, los animales, los rezanderos, sin descuidar la palabra que se reproduce en los rezos, los santiguos, cánticos, voces y recuerdos de la tradición mediadora.

En estas formas otras de conocimiento y su articulación se refleja una construcción decolonial de saber manifestada en modos y condiciones de pensar diferentes, se considera en este sentido, por ejemplo, roles, valores y poderes concedidos a los mediadores o intermediarios para la sanación, los materiales, palabras y discursos, los bienes de la naturaleza, y a las maneras de conectarse con el medio para atender la salud, la alimentación y el cuidado de los niños. Para los pueblos afro, todo este conjunto ha funcionado históricamente como estrategias propias de supervivencia cultural que han garantizado la adquisición, la preservación, valoración y transmisión de la cultura.

\section{Normas y principios para la convivencia social}

En los primeros años de vida, desde el seno familiar se le enseña a los menores principios de convivencia e inserción en sociedad. Siguiendo la información de los maestros, los valores fundamentales que se difunden en el marco de las normas y principios comunitarios son la consideración y el respeto, valores que logran visualizarse en el acompañamiento en las situaciones de dolor, padecimiento o pérdida de algún familiar, en la posibilidad de hacer favores, disponerse para encargos o actuar afectivamente con las personas que constituyen de alguna forma su familia extendida. De allí que, por ejemplo, en San Basilio de Palenque los niños y jóvenes Ilamen tíos o tías a los mayores y adultos del pueblo, independiente de cualquier vínculo consanguíneo; que en María La Baja, en otros tiempos, los niños se acostumbraran a besar la mano de sus padrinos o madrinas, o de otros mayores cuando estos llegaban de vista o se encontraran en cualquier lugar de la comunidad. O el hecho de guardar un "medio luto" ante el fallecimiento de un miembro "lejano/ cercano" de la familia.

De igual forma, a los infantes se les exigía -aún se mantiene esta práctica- realizar saludos o cortesías cuando: deambulaban por las calles, alguien visitaba sus casas o en caso de que fueran de visita a otros lugares. En caso de no hacerlo se les reprendía públicamente y se les exhortaba a realizar la acción no ejecutada.

Hasta hace algunos años para los niños el espacio de circulación de los adultos se constituía en un escenario vedado, una especie de lo prohibido, algo así como "juntos pero no revueltos". Cuando los niños invadían el espacio de los "grandes", con una mirada o con la realización de algunos gestos por parte de los adultos, los menores comprendían que su presencia implicaba su retirada. La intención de los adultos con el uso de estos lenguajes no verbales era lograr que se comprendieran los significados implicados para que no se volviera a reproducir el comportamiento reprochado.

La referencia a sucesos misteriosos, los relatos de la Mohana y el Mohán, las advertencias alrededor de las horas, los lugares, a la falta de compañía, tienen una clara finalidad dentro de la comunidad, este es, el control social para prevenir el peligro y las acechanzas que pudieran acontecer cuando se circula solitariamente por sitios vedados, cargados de hechos enigmáticos o cuando se desobedecían los consejos de los padres o las alertas comunitarias. Los relatos y ejemplificaciones forman parte de las pedagogías de la oralidad que se instala en la memoria colectiva para evitar, en lo posible, situaciones trágicas sobre todo en los más indefensos, en este caso niños y niñas afrodescendientes.

Frente a los hechos de rebeldía, un dato curioso ocurría en algunos corregimientos y veredas de San Onofre, en estos lugares se acostumbraba a colocar a los niños indisciplinados cerca de una planta de ají picante; habitualmente esta acción era realizada en horas de la mañana y con ello se buscaba contribuir a mejorar 
el comportamiento de los pequeños, pues la picazón producidos podría entretener por largas horas a los indisciplinados.

Las prácticas y saberes que se tejen en el contexto de la convivencia social, han girado alrededor de la formación para la convivencia y el accionar para comportarse ante el público. En las comunidades afrodescendientes, la voz de los mayores y de otras personas del entorno no se constituía en límite para reprender, aconsejar o rendir pleitesías -aun cuando la persona mayor no perteneciera al núcleo familia-, la justicia ancestral con sus reglas consuetudinarias era asumida como mecanismos de control social y se exigía su cumplimiento y aprendizaje. La reproducción de leyendas, la creación de personajes míticos, la creación de léxico sancionador se constituyeron en los mecanismos para difundir el conocimiento y para reaccionar en situaciones concretas. La oralidad en su esencia se convertía en una herramienta valiosa para tal fin.

\section{Rituales para la conservación de la vida y la compañía ante la muerte}

Alrededor de la vida y la muerte se han elaborado ancestralmente un sinnúmero de ritos y prácticas de gran trascendencia. En los pueblos afrodescendientes de San Onofre, Mahates, María La Baja y Palenque, estas elaboraciones, como se ha señalado, se han construido en torno a la cosmovisión y a la espiritualidad en estrecha conexión con la naturaleza y sus variados elementos. Además se han nutrido del sincretismo que recoge la sabiduría popular, lo mágico, la religiosidad, entre otros aspectos.

Los rituales de vida y muerte, en torno a los niños de estos pueblos afro, se han recreado para conservar su existencia en el mundo de los vivos, pero también para acompañarlos cuando mueren. Los rituales de vida encuentran su pertinencia en el espíritu protector favorecedor para cada miembro de la comunidad; el propósito es "espantar/alejar" energías, espíritus, espantos o acechanzas. Los rituales de muerte se han elaborado para acompañar y habilitar una mejor correspondencia entre los difuntos, el mundo en cual ellos habitan y los vivos.
Por lo misterioso y trascendente del tema son pocos los datos que sin temor fueron compartidos, entre estos se destacan:

\section{La estancia entre los vivos de los niños}

\section{afrodescendientes}

Para lograr la inmunidad y poder mantenerse en el mundo de los vivos, los mayores a través de su oralidad en las comunidades afrodescendientes han difundido a las distintas generaciones gran confianza alrededor de objetos materiales, atavíos, palabras, "rezos" que se convierten en la "contra" para la acechanza o para la cura de ciertas enfermedades. Así, por ejemplo, a los niños se les viste con mates, semillas, colmillos, escapulario o con pulseras, estos atavíos deben ser "arreglados", "rezados", por rezanderos o curanderas. Tales amuletos son depositados en collares o brazaletes que se colocan a los niños desde los primeros días de nacidos; por lo general, las cuerdas o cintas usadas para ello son de color rojo, tonalidad también utilizada en las prendas de vestir para evitar que los duendes o brujas chupen la sangre de los menores.

Para instalar con mayor fuerza a los infantes en el mundo de los vivos, se coloca -sobre todo en las zonas más rurales- hojas de la planta de ruda debajo de la cama o tijeras debajo de la almohada; el propósito es dispersar cualquier intención de desplazar a los niños a otros lugares distintos al mundo de los vivos. También se acostumbraba lanzar, en forma de cruz sobre las terrazas de las casas, los restos del agua usados después de haber aseado al bebé.

Con el entierro del ombligo en el patio de las viviendas, se podía garantizar que los infantes tuvieran una vida digna, coherente con el propósito de formación familiar; asignar padrinos y madrinas desde antes del nacimiento, al igual que realizar el santiguo de los siete viernes previos a la Semana Santa, podían constituirse en medios para la defensa de los misterios de la noche, las ánimas y los espíritus deambuladores, razón por la cual no se podía dejar a los pequeños solos, durante ciertas horas del día, puntualmente a las seis de la mañana, las doce del mediodía y las seis de la tarde. 
El vínculo sacramental que se pacta a través del bautismo entra también al juego de las estrategias para la supervivencia en la niñez. Padrinos y madrinas fungen como "sacramento del altar" cumpliendo una misión importantísima para evitar desapariciones misteriosas, proteger ante calamidades domésticas y asumir compromisos en la orientación de los apadrinados. Al establecerse el compadrazgo se entablan lazos sagrados enmarcados en la solidaridad, el respeto y el amor. Los padrinos son la primera opción para acoger a los niños en caso del fallecimiento de los padres; además, estas personas se constituyen en una especie de mediadores para la protección, de los infantes, del mundo del Mohán o de los seres sobrenaturales que encantan a los pequeños para llevarlos a sus subterráneas moradas.

En caso de ser raptados por estos seres, algunas de las prácticas de la tradición revelan que el papel de la madrina o sacramento del altar para romper con el hechizo; a la comadre le corresponde vociferar el nombre de su ahijado o ahijada cerca de la iglesia, o por los lugares en donde se sospecha ha desaparecido, para lograr atraerlo de nuevo con su familia.

\section{Las decisiones en torno a la muerte}

En cuanto a las decisiones en torno a la muerte, de acuerdo con las experiencias y vivencias recogidas, se señalan dos tendencias que sintetizan el hacer frente a este hecho: por un lado, la ritualidad específica que acompaña la muerte de un niño, y por otro, los eventos preventivos que se construyen cuando fallece un mayor cercano a la vida del infante.

En el primer caso, cuando son los pequeños los que fallecen, se describen acciones que van desde el bautizo del niño antes de enterrarlo en la eventualidad de que este no haya recibido el sacramento, antes de que sean introducidos en el ataúd, se les coloca "palitos en los ojos y se les ata de manos y pies", hasta preparar un cortejo de despedida con niños y niñas vestidos de blanco.

Así mismo se han conservado recomendaciones que indican, por ejemplo: no llorar por esta muerte, porque se corre el riesgo de dejar el alma en pena; tampoco usar vestuarios que simbolicen luto, o sepultar a los fallecidos en el patio de las casas.
En la situación de que el difunto fuera o sea alguien cercano a la cotidianidad de los menores, se acostumbra en estas poblaciones a tomar las medidas de los infantes y depositarlas dentro del ataúd, esto se hace para evitar que "el muerto se lo lleve". De igual forma, se advierte despertar a los niños en el momento que el entierro salga de las casas.

Las tareas para conservar la vida y acompañar en la muerte son realizadas por expertos y expertas que bajo los rituales ancestrales suelen orientar a las familias en las situaciones descritas.

\section{A modo de conclusión}

Algunas comunidades afrodescendientes de los departamentos de Bolívar y Sucre han generado ancestralmente formas de conocimiento poco reconocidas por las lógicas hegemónicas que las han descocido históricamente. Las reflexiones y aportes del paradigma decolonial se constituyen, en este sentido, en un referente clave para comprender en estas lógicas representaciones y simbolizaciones afro, otras formas de saber y ser en espacios culturales distintos.

La sabiduría ancestral de las poblaciones afro se visualiza en la cosmovisión, los discursos y prácticas que coloca en superficie el legado depositado y la posibilidad de recurrir a la naturaleza, a lo astros, a los recursos naturales, a los mayores, a la palabra y a sus mediadores como muestra de las elaboraciones de un conocimiento creado en las experiencias de vida comunitaria. Este conjunto de saberes se contextualizan, poseen historia y se rebelan cuando se les invisibiliza y margina. Por medio de la tradición oral y apoyándose en la memoria colectiva, histórica y ancestral, su difusión se extiende y perdura, logrando que en situaciones concretas sean retomados y validados en la dimensión que la cultura les ha otorgado.

Las tradiciones en torno la infancia en los pueblos revelan un invaluable patrimonio de la sabiduría de las comunidades; el rescate en las memorias de este acumulado aporta indiscutiblemente en la comprensión de gran parte de los fundamentos y principios que subyacen en torno a las prácticas y saberes relacionados con la concepción de infancia y todas sus implicaciones. 
Los docentes etnoeducadores, en su rol de mediadores en la construcción de la identidad nacional, basada en la valoración y respeto de la diversidad étnica y cultural del país, deberían considerar el conjunto de saberes de los cuales son herederos y depositarios no solo como referentes de su identidad afro, sino también como material importante para la articulación curricular en la conexión comunidad/escuela, pilar del desarrollo de proyectos etnoeducativos.

Gran parte de las tareas que se proponen dentro del proyecto etnoeducativo están orientadas al reconocimiento, salvaguarda y difusión respetuosa de las formas otras de saber, para impulsar su valoración, tanto en el interior del espacio cultural afro como por fuera de este. Se exhorta entonces a la comunidad, a los docentes, líderes a continuar indagando en esa memoria histórica ese patrimonio de conocimientos para ponerlos a disposición de la comunidad. En ese sentido, se requiere la validación en el contexto escolar de las pedagogías otras, que permita la comunicación, el intercambio de saberes y la participación de "ese otro" que crece y vive en un mundo cuyos significados provienen de objetos, rituales y palabras que aparecen como elementos de la cultura para construir un currículo etnoeducativo, intercultural trascendente, pertinente, incluyente y dialogante.

\section{Referencias}

Aguilar M. y Rodríguez, L.F. (1999). Tradición oral y pedagogía propias. En Culturas, lenguas y educación: Simposio de Etnoeducación, vIII Congreso de Antropología. Memorias. (pp.81 -91).Bogotá: Universidad de los Andes.

Berman, E. (2011). Multiculturalismo y reconocimiento étnico. Debates actuales en el Caribe Colombiano. Cartagena de Indias: Laboratorio Iberoamericano de Investigación e Innovación en cultura y desarrollo L+ld, Universidad Tecnológica de Bolívar.

Geertz, Clifford. (2003). La interpretación de las culturas (12 reimpresión.). Barcelona: Gedisa editorial.

Hernández, R.; Guerrero, C.I. y Pérez, J. (2008). Palenque, historia libertaria, cultura y tradición. Cartagena: Organización Digital Casa Editorial.

Hernández, R. (2015). Cultura, desarrollo, movimientos social afrocolombiano y democracia. Cartagena: Instituto de Investigación y Educación Manuel Zapata Olivella.

Hernández, R. et al. (2016). Método de consulta a la memoria colectiva y perspectivas de la investigación. Cartagena: Instituto de Investigación y Educación Manuel Zapata Olivella.

Molano, O. (2006). La identidad cultural, uno de los detonantes del desarrollo territorial. Recuperado de http://procasur.cl/fida/ t2.pdf. Consultado mayo 17 de 2011.

Restrepo, E. y Rojas, A. (2010) Inflexión decolonial: fuentes, conceptos y cuestionamientos. Colección Políticas de la Alteridad. Popayán: Editorial Universidad del Cauca.

Valverde, A. (2005). La tradición oral: entre la enseñanza y la historia. Recuperado de revistas.utadeo.edu.co/index.php/INT/article/ download/807/817

Walsh, C. (2004). Colonialidad, conocimiento y diáspora afroandina: construyendo etnoeducación e interculturalidad en la universidad. En: E. Restrepo y A. Rojas (ed.). Conflicto e (in) visibilidad. Retos en los estudios de la gente negra en Colombia (pp. 331-346). Popayán: Editorial Universidad del Cauca, Colección Políticas de la Alteridad.

Walsh, C. (ed.) (2013). Pedagogías decoloniales. Prácticas insurgentes de resistir, (re)existir y (re)vivir. Tomo 1. Serie pensamiento decolonial. Quito: Ediciones Abya-Yala. 


\section{Diálogo del conocimiento}

Este escrito trata sobre algunas prácticas, saberes y actuaciones en torno a cómo las comunidades afrodescendientes de algunos municipios del norte de los departamentos de Bolívar y de Sucre cuidan, protegen, forman e inician socialmente a los niños.

La información que se analiza y reseña en el texto corresponde a los recuerdos, experiencias, prácticas y saberes vigentes por parte de maestros afrodescendientes, negros y palenqueros, que habitan y laboran en estas comunidades en María La Baja, Palenque, Mahates y San Onofre. Con ellos se desarrolló un proceso de cualificación, a partir del cual se generaron espacios de diálogo para indagar sobre la memoria colectiva acerca de algunos aspectos de relación entre infancia, territorio, prácticas culturales y simbólicas, en vínculo con las referencias a la identidad, la familia y a la tradición oral, y difundidos a través de las pedagogías propias, las cuales permiten acercamientos a la forma en que se concibe la niñez en correspondencia con una particular visión de mundo, que determina imaginarios, relaciones y roles sociales bajo los parámetros de la cultura.

Desde una aproximación a las experiencias de atención y protección de los niños afrodescendientes, el documento asume la niñez como parte fundamental del ciclo de vida en estas comunidades, y da cuenta de las conexiones que en este aspecto se han tejido en torno a la existencia, en estrecho vínculo con un sinnúmero de aspectos desde la cosmovisión de la sabiduría ancestral, los bienes de la naturaleza y la experiencia comunitaria, tales como: el tiempo, los símbolos, el cuerpo, los astros, el ecosistema, la muerte, la espiritualidad (ánimas y difuntos, rezos, sueños, revelaciones, herbología, sanación), las normas, los valores e ideales, el cuidado, el alimento, la salud y la medicina tradicional como prácticas curativas. Estas se dimensionan en el proceso de crianza y socialización de los infantes, quienes se desarrollan con un fuerte compromiso con la familia, la comunidad y sabedores, desde el momento de la gestación hasta cuando la madre da a luz.

\section{Normas y principios para la convivencia social}

En los primeros años de vida, desde el seno familiar al menor se le enseñan principios de convivencia e inserción en sociedad, precisándoles que para la convivencia juntos es necesario aprender y ajustarse a ciertos modelos de comportamiento.

Siguiendo la información de los maestros, los valores fundamentales que se difunden en el marco de las normas y principios comunitarios son: la consideración y el respecto, los cuales logran visualizarse en el acompañamiento en las situaciones de dolor, padecimiento o pérdida de algún familiar, en la posibilidad de hacer favores, disponerse para encargos o actuar afectivamente con las personas que constituyen, de alguna forma, su familia extendida. De allí que, por ejemplo, en San Basilio de Palenque, los niños y jóvenes llamen tíos o tías a los mayores y adultos del pueblo, independiente de cualquier vínculo consanguíneo; que en María La baja, en otros tiempo, los niños se acostumbraran a besar la mano del padrino o de la madrina, o de otros mayores cuando estos llegaban de vista o se encontraran en cualquier lugar de la comunidad; o el hecho de guardar un medio luto ante el fallecimiento de un miembro lejano/cercano de la familia.

\section{Rituales para la conservación de la vida y la compañía ante la muerte}

Alrededor de la vida y la muerte se han elaborado ancestralmente un sinnúmero de ritos y prácticas de gran trascendencia. En los pueblos afrodescendientes de San Onofre, Mahates, María La Baja y Palenque, estas elaboraciones, como ya se ha señalado, se han construido en torno a la cosmovisión y a la espiritualidad en estrecha conexión con la naturaleza y sus variados elementos. Además, se han nutrido del sincretismo que recoge la sabiduría popular, lo mágico, la religiosidad, entre otros aspectos.

Los rituales de vida y muerte en torno a los niños de estos pueblos afro, se han recreado para conservar su existencia en el mundo de los vivos, pero también para acompañarlos cuando mueren. Dichos rituales encuentran su 
pertinencia en el espíritu protector favorecedor para cada miembro de la comunidad; el propósito es espantar/ alejar energías, espíritus, espantos o acechanzas. Los rituales de muerte, por su parte, se han elaborado para acompañar y habilitar una mejor correspondencia entre los difuntos, el mundo en cual ellos habitan y los vivos.

Por lo misterioso y trascendente del tema, son pocos los datos que sin temor son compartidos, a continuación se presentan los datos recogidos al respecto.

\section{La estancia entre los vivos de los niños afrodescendientes}

Para lograr la inmunidad y poder mantenerse en el mundo de los vivos, los mayores, a través de su oralidad en las comunidades afrodescendientes, han difundido a las distintas generaciones gran confianza alrededor de objetos materiales, atavíos, palabras, rezos que se convierten en la contra para la acechanza o para la cura de ciertas enfermedades. Así, por ejemplo, a los niños se les viste con mates, semillas, colmillos, escapularios, pulseras; estos deben estar arreglados, rezados, por rezanderos o curanderas. Estos amuletos son depositados en collares o brazaletes que se colocan a los niños desde los primeros días de nacidos; por lo general las cuerdas o cintas usadas para ello son de color rojo, tonalidad también utilizada en las prendas de vestir para evitar que los duendes o brujas chupen la sangre de los menores.

\section{Las decisiones en torno a la muerte}

En cuanto a las decisiones en torno a la muerte, de acuerdo con las experiencias y vivencias recogidas, dos tendencias sintetizan el hacer frente a este hecho: por un lado, la ritualidad específica que acompaña la muerte de un niño, y por otro, los eventos preventivos que se construyen cuando fallece un mayor cercano a la vida del infante.

Dinah Margarita Orozco Herrera 